\title{
INTERSECCIONALIDADE EM UMA ZONA DE SACRIFÍCIO DO CAPITAL: A EXPERIÊNCIA DE MULHERES NEGRAS, QUILOMBOLAS E MARISQUEIRAS DA ILHA DE MARÉ, BAÍA DE TODOS OS SANTOS (BAHIA, BRASIL)
}

\author{
Patricia Rodin *** \\ *Universidade Federal do Rio de Janeiro, Instituto de Pesquisa e Planejamento Urbano e Regional, Rio de \\ Janeiro, RJ, Brasil \\ ${ }^{* *}$ Instituto Brasileiro do Meio Ambiente e dos Recursos Naturais Renováveis, Rio de Janeiro, RJ, Brasil
}

\begin{abstract}
Resumo
Este artigo se baseia em uma pesquisa empírica cujo objetivo é analisar, a partir de uma perspectiva interseccional, como as mulheres negras, quilombolas e marisqueiras de duas comunidades da Ilha de Maré (Baía de Todos os Santos, Salvador, Bahia) são afetadas pela ocupação de seu território pela cadeia petrolífera. A compreensão da complexidade da experiência que essas mulheres vivenciam em seu território de vida, no atual contexto de conflito ambiental, só pode ser alcançada considerando a intersecção dos marcadores de raça, gênero, classe e o que aqui denominamos de modo de vida ligado ao meio ambiente.

Palavras-chave

Interseccionalidade; Gênero; Marisqueiras; Conflito ambiental; Cadeia petrolífera; Racismo; Ilha de Maré.
\end{abstract}




\title{
INTERSECTIONALITY IN A SACRIFICE ZONE OF CAPITAL: THE EXPERIENCE OF BLACK WOMEN, QUILOMBOLAS AND GLEANERS, ON ILHA DE MARÉ, IN TODOS OS SANTOS BAY (BAHIA, BRAZIL)
}

\author{
Patricia Rodin *** \\ *Universidade Federal do Rio de Janeiro, Instituto de Pesquisa e Planejamento Urbano e Regional, Rio de \\ Janeiro, RJ, Brazil \\ ${ }^{* *}$ Instituto Brasileiro do Meio Ambiente e dos Recursos Naturais Renováveis, Rio de Janeiro, RJ, Brazil
}

\begin{abstract}
This article, based on an empirical research project, aims to analyze, from an intersectional perspective, how Black women, quilombolas and gleaners, from two communities on Ilha de Maré (in Todos os Santos Bay, Salvador, Bahia) have been affected with the occupation of their territory by a petroleum supply chain. Understanding the complexity of the experience that these women have come up against in the territory where they live, due to a context of environmental conflict, may only be achieved by considering the intersectionality of race, gender, and class, and through what we have termed as a way of life linked to the environment.

Keywords Intersectionality; Gender; Gleaners; Environmental conflict; Petroleum supply chain; Racism; Ilha de Maré.
\end{abstract}




\section{INTERSECCIONALIDADE EM UMA ZONA DE SACRIFÍCIO DO CAPITAL: A EXPERIÊNCIA DE MULHERES NEGRAS, QUILOMBOLAS E MARISQUEIRAS DA ILHA DE MARÉ, BAÍA DE TODOS OS SANTOS, SALVADOR, BAHIA, BRASIL}

Patricia Rodin

1. Introdução

O presente artigo tem como objetivo analisar, a partir de uma perspectiva interseccional, como as mulheres negras, quilombolas e marisqueiras de duas comunidades da Ilha de Maré (baía de Todos os Santos, Salvador, Bahia) - Porto dos Cavalos e Martelo - são afetadas pela ocupação de seu território pela cadeia petrolífera. Trata-se de uma pesquisa empírica, baseada num trabalho de campo de imersão na localidade, que enseja contribuir para a compreensão de como mulheres pertencentes a comunidades tradicionais, mais especificamente, de pesca artesanal, têm tido diferentes dimensões de suas vidas afetadas por conflitos ambientais. Aqui nos detemos nas implicações do petróleo tanto nos corpos quanto nos territórios de vida e de trabalho dessas mulheres, ambos indissociáveis.

Por conflitos ambientais, compreendemos, conforme Acselrad (2004, p. 26):

Aqueles [conflitos] envolvendo grupos sociais com modos diferenciados de apropriação, uso e significação do território, tendo origem quando pelo menos um dos grupos tem a continuidade das formas sociais de apropriação do meio ameaçada por impactos indesejáveis - transmitidos pelo solo, água, ar ou sistemas vivos - decorrentes do exercício das práticas de outros grupos.

\footnotetext{
1. Agradeço às mulheres de Porto dos Cavalos e Martelo por terem acolhido a mim e a minha pesquisa, em especial, à Eliete Paraguassu, por ter aberto sua casa para minha estada na comunidade, entre outras tantas trocas. Agradeço à minha orientadora, Cecília Campello do Amaral Mello, pela orientação e revisão na redação deste artigo, assim como aos pareceristas da RBEUR, e ao Instituto Brasileiro do Meio Ambiente e dos Recursos Naturais Renováveis (IBAMA), por ter me concedido licença para cursar o doutorado.
} 
Uma grande quantidade de comunidades de pesca artesanal encontra-se atualmente envolvida em conflitos ambientais, como apontam o relatório Conflitos Socioambientais e Violações de Direitos Humanos em Comunidades Tradicionais Pesqueiras no Brasil, elaborado pela Comissão Pastoral da Pesca (2016) e a análise de Walter et al. (2019) a partir do Mapa da Injustiça Ambiental e Saúde no Brasil, produzido pela Fiocruz. Vale destacar que, do conjunto de conflitos ambientais identificados em âmbito nacional pelo referido mapa, apenas 0,34\% fazem referência explícita às mulheres (PACHECO; FAUSTINO, 2013 apud WALTER et. al., 2019).

Assim, é premente a busca da compreensão sobre a forma como as mulheres negras, sobretudo as de comunidades de pesca artesanal - importante sujeito político presente ao longo de toda a costa brasileira -, vivenciam esses cenários de conflitos ambientais. Para tanto, fazemos uso da abordagem analítica da interseccionalidade, para a qual a experiência de vida dos grupos sociais é indissociável do entrecruzamento de diferentes eixos de opressão, que, por sua vez, não podem ser entendidos isoladamente, a saber: raça, classe, gênero e nacionalidade. Em outras palavras, essa perspectiva analítica lança luz sobre o fato de que o posicionamento dos grupos sociais na matriz de relações de poder da sociedade é definido pelo cruzamento desses eixos, e não por apenas um deles, nem pelo seu simples somatório, como se atuassem de forma independente (COLLINS, 2000; CRENSHAW, 2002). Nesse sentido, a realidade vivida por cada grupo se dá em função do entrecruzamento complexo de tais eixos, que, de acordo com o contexto, apresentam diferentes possibilidades de combinações.

Importa destacar que, apesar de a jurista negra norte-americana Kimberlé Crenshaw ter exercido um papel fundamental na formulação teórica desse conceito e paradigma analítico, cunhando-o pelo termo interseccionalidade, intelectuais brasileiras, como Lélia Gonzalez (1984) e Luiza Bairros (1995), já articulavam em suas análises o sexismo, o racismo e a exploração capitalista para dar inteligibilidade à experiência das mulheres negras brasileiras, sem, contudo, fazer uso de tal vocabulário teórico. Assim sendo, a análise interseccional se configura como uma forma histórica de as mulheres negras localizarem sua experiência na matriz de relações de poder da sociedade.

Aqui, consideramos que a experiência das mulheres da Ilha de Maré só pode ser compreendida levando-se em conta o entrecruzamento entre gênero, raça e classe - eixos de opressão estruturantes -, junto de um marcador específico que conforma a realidade vivida por elas: o modo de vida ligada ao meio ambiente.

Este trabalho dialoga com os campos mais amplos dos estudos feministas e interseccionais, de gênero e pesca e dos conflitos ambientais. Dessa forma, ele visa 
contribuir, por um lado, para a inclusão do universo das mulheres da pesca artesanal no campo das pesquisas feministas e interseccionais, as quais, historicamente, têm se debruçado sobre o universo das mulheres de modo de vida urbano, e, por outro, para a inserção do paradigma da interseccionalidade no âmbito dos trabalhos de gênero e pesca e de conflitos ambientais, perspectiva que até o momento não tem sido devidamente representada nessas áreas.

As investigações sobre pesca e gênero, apesar de ainda ocupar um lugar marginal no campo da pesquisa sobre pesca, têm contado, desde os anos 2000, com um aumento na sua produção (MANESCHY et al., 2012). Seu foco principal tem sido a análise da divisão sexual e espacial do trabalho e seus desdobramentos, por exemplo, os temas da falta de reconhecimento das mulheres como trabalhadoras da pesca e, ao mesmo tempo, do papel fundamental delas na conservação dos saberes tradicionais e manutenção do modo de vida das comunidades (SOUZA; RIBEIRO; MARTINEZ, 2019).

Já os estudos dos conflitos ambientais, por um lado, objetivam explicitar que a relação sociedade-natureza é informada por relações assimétricas de poder, demonstrando empiricamente que as desigualdades ambientais são um correlato das desigualdades sociais - politizando, assim, o debate ambiental. Por outro lado, eles intentam contribuir para a compreensão da lógica que subjaz os conflitos ambientais e de como neles se posicionam as comunidades e grupos afetados por atividades causadoras de danos socioambientais.

Todavia, no Brasil, as análises realizadas nesse campo têm conferido à variável "classe” a quase exclusividade explicativa das desigualdades ambientais identificadas. É notável a sub-representação das categorias explicativas de raça e gênero em seus trabalhos e, em particular, da abordagem interseccional. Entre aqueles que a incorporaram, podemos citar as contribuições de Maia (2021), Furtado (2018) e Barcellos (2008). Ademais, vale sublinhar que, mais recentemente, as Missões de Investigação e Incidência da Relatoria do Direito Humano ao Meio Ambiente da Plataforma Dhesca, juntamente com a Rede Brasileira de Justiça Ambiental (FAUSTINO; FURTADO, 2013a; 2013b) e organizações que atuam diretamente com comunidades afetadas por grandes projetos, têm realizado um importante movimento no sentido de evidenciar os diferentes impactos dessas ações na vida e nos corpos de mulheres racializadas, pertencentes a comunidades tradicionais, indígenas, camponesas e periféricas (MAB, 2011; PACS, 2017; INESC, 2020).

Atualmente, ainda de forma muito incipiente, tem sido debatida a construção do campo da Ecologia Política Feminista (EPF) latino-americana (GARCIA; CUEVAS, 2017; OYARZÚN; ALVAREZ, 2019), em diálogo com os conflitos ambientais. A EPF se 
desenvolveu inicialmente no Norte Global, nutrindo-se de diferentes correntes e teorias do feminismo e das ciências sociais para tratar das relações que envolvem gênero e ambiente (OYARZÚN; ALVAREZ, 2019). Ela caracteriza-se por ser um campo aberto e em expansão, abarcando diferentes linhas teórico-metodológicas, todavia, grande parte de seus estudos tem buscado compreender como as relações de poder, no que se refere ao acesso, controle e apropriação de recursos do ambiente, se articulam com gênero e como as intervenções antrópicas, causadoras de conflitos ambientais, se cruzam com as hierarquias de gênero das comunidades afetadas (ELMHIRST, 2015; 2018). Para tal, eles partem da investigação sobre a construção de gênero na sua relação com o ambiente, englobando escalas mais próximas no interior das comunidades e/ou das famílias.

Este artigo se filia a tal linha da EPF. No entanto, como ele se desenvolve no Brasil, país de herança colonial forjado na escravidão, a categoria raça assume centralidade, uma vez que esta última atua na configuração da estrutura, organização e dinâmica das relações sociais e, logo, na definição do acesso, uso e apropriação dos recursos ambientais pelas mulheres, variável que os estudos da EPF do Norte Global não têm levado em consideração (MOLLET; FARIA, 2013). Assim, é um trabalho que se soma ao incipiente campo da EPF latino-americana.

Cabe destacar que as próprias mulheres quilombolas da Ilha de Maré vêm denunciado na arena pública, reiteradamente, que elas têm sido submetidas a um processo de racismo ambiental desde a década de $1950 .^{2}$ Compreendemos que a reivindicação do uso desse conceito para caracterizar a injustiça ambiental a que estão submetidas tem como objetivo lançar luz para a centralidade da raça e do racismo estrutural historicamente constituído na sociedade brasileira, os quais, segundo a leitura de mundo dessas mulheres, se configuram como fatores determinantes para a conformação da realidade vivida, incluindo aí a desigualdade ambiental.

Na mesma direção, os poucos trabalhos que até hoje incorporaram a categoria raça na análise de conflitos ambientais no Brasil, como PoEMAS (2015) e Mello (2015), chamam a atenção para o fato de que as populações diretamente afetadas pelo crime ambiental da Samarco/Vale/BHP eram majoritariamente negras - como aquelas da comunidade de Bento Rodrigues, que era composta por $84,5 \%$ de pessoas negras e foi completamente destruída. Desse modo, eles apontam para a centralidade das desigualdades raciais na distribuição e intensidade dos impactos

2. Conceito cunhado na década de 1980, pelo Movimento Negro norte-americano, que na época também se encontrava envolvido na luta pelos direitos civis, para descrever o fenômeno em que os grupos racializados nos Estados Unidos eram submetidos, de forma desproporcional, a impactos e riscos de atividades poluidoras. 
ambientais identificados. Considerando que as relações raciais se constituem como relações de poder que estruturam e medeiam as relações sociais no Brasil e que os conflitos ambientais emergem em situações de relações assimétricas de poder, sustentamos que não se pode tratar a desigualdade ambiental produzida pelos conflitos dissociada da desigualdade racial presente no Brasil, em particular na baía de Todos os Santos.

Por fim, ressaltamos que o enfrentamento protagonizado pelas mulheres marisqueiras da Ilha de Maré contra empresas, que despejam em seu território de vida rejeitos contaminados, e contra o Estado, que se omite em exercer seu papel regulatório, chamando a atenção para o racismo ambiental que afeta de forma mais aguda seus corpos e suas vidas, tem dado novos contornos para a ação política, associando a luta por justiça ambiental com a luta feminista e antirracista. Essas marisqueiras fazem parte de um movimento maior que tem se desenvolvido nas últimas décadas na América latina, onde um expressivo número de mulheres negras, indígenas, camponesas, pertencentes a comunidades tradicionais e urbanas periféricas, tem protagonizado o enfrentamento e a luta contra o modelo de desenvolvimento hegemônico, em defesa de seus territórios e comunidades (SVAMPA, 2019). Nesse sentido, tal movimento revela que a interseccionalidade de marcadores como raça, gênero e classe, embora vulnerabilize de forma mais profunda as mulheres aqui mencionadas, também potencializa a agência delas.

\section{Ilha de Maré: território quilombola, da pesca artesanal e zona de sacrifício da cadeia petrolífera}

A Ilha de Maré faz parte do Recôncavo baiano, região formada pelos municípios do interior e do entorno da Baía de Todos os Santos (BTS), excluindo-se a capital Salvador. Ela está localizada na porção noroeste da BTS, em frente à Baía de Aratu (Figura 1); já as comunidades de Porto dos Cavalos e Martelo se localizam ao Norte da ilha. Apesar da distância, a Ilha de Maré pertence à cidade de Salvador. De acordo com dados do último censo (IBGE, 2010), ela possui uma população de 6.434 habitantes, sendo o bairro com maior concentração de população negra dessa cidade - com 93\% de seus moradores se declarando pretos ou pardos -, e aquele que apresenta um dos piores Índices de Desenvolvimento Humano (IDH). 


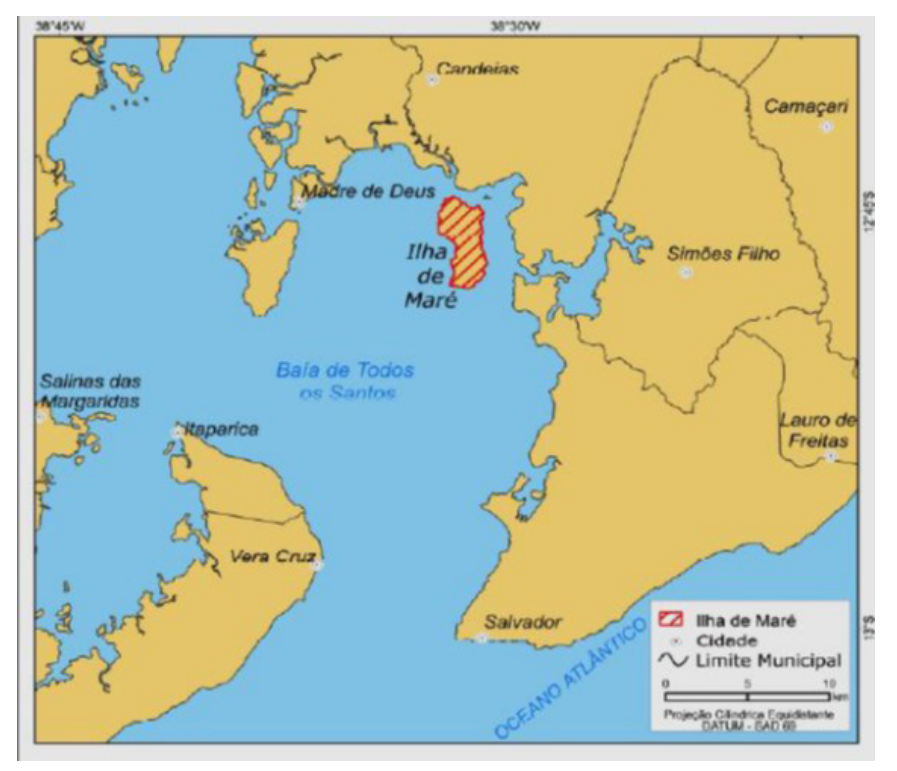

Figura 1. Mapa com a localização da Ilha de Maré

Fonte: Base Cartográfica da Bahia, 2001 apud OBTEIA, 2014.

A ilha é formada por 10 comunidades; seis delas, incluindo Porto dos Cavalos e Martelo, foram, entre 2004 e 2005, reconhecidas pela Fundação Cultural Palmares (FCP) como comunidades remanescentes de quilombos. A partir desse reconhecimento, elas entraram com o pedido de regularização do território quilombola de Ilha de Maré no Instituto Nacional de Colonização e Reforma Agrária (INCRA), o qual não foi finalizado até a data de publicação deste artigo. As comunidades certificadas vivem da pesca artesanal, da agricultura familiar e do artesanato, sendo que Porto dos Cavalos e Martelo vivem exclusivamente da pesca.

Segundo relato do Sr. Djalma, um mais velho e liderança local, e informações do Relatório Técnico de Identificação e Delimitação da Comunidade Quilombola de Ilha de Maré (INCRA, 2016), as comunidades quilombolas foram formadas por negros escravizados que fugiram de engenhos de outras áreas e de embarcações que naufragaram em suas proximidades, bem como por negros escravizados nos engenhos localizados na própria ilha, os quais lá permaneceram após a abolição.

A Ilha de Maré, tal como o Recôncavo como um todo, teve seu território ocupado, de meados do século XVI ao século XVIII, por uma rentável economia açucareira de base escravista. Mesmo com a diminuição de sua importância no cenário econômico mais amplo, esse modelo de produção manteve-se praticamente inalterado no território até a abolição, em 1888 (BARICKMAN, 1999). Assim, no pós-abolição, o Recôncavo se encontrava ocupado, predominantemente, por comunidades negras que viviam da agricultura familiar e/ou da pesca artesanal (FRAGA FILHO, 2004), de modo que, na contemporaneidade, também se reconhecem como 
remanescentes das comunidades de quilombos, denominação estabelecida pela Constituição de $1988 .^{3}$

No entanto, a partir da década de 1950, houve uma mudança abrupta na forma de ocupação e apropriação do território do Recôncavo, em função da descoberta do petróleo, seguida do estabelecimento da primeira cadeia petrolífera do país, que afetou diretamente - e afeta cada vez mais - a realidade das comunidades aí estabelecidas. A produção de petróleo nos campos terrestres do Recôncavo favoreceu a instalação da Refinaria Landulpho Alves e do Terminal Marítimo de Madre de Deus, para embarque e desembarque de petróleo e seus derivados, em 1950, do Centro industrial de Aratu em 1967, do Porto de Aratu em 1975 e do Polo Petroquímico de Camaçari em 1978, além de estruturas menores, mas bastante impactantes (como dutos e reservatórios), para servir a essa cadeia.

O cenário que encontramos atualmente no Recôncavo é da ocupação e apropriação, principalmente das margens da BTS, por um complexo industrial relacionado, sobretudo, a atividades da cadeia petrolífera, interligadas por uma rede de oleodutos e gasodutos que atravessam a baía. Desde 1955, aproximadamente, a Ilha de Maré - em particular, a comunidade do Martelo - é um desses territórios ocupados. Nela, estão instalados poços de petróleo terrestres conectados a dutos, expostos na superfície, que atravessam a comunidade, levando o gás e o óleo aí extraídos para estações de armazenamento localizadas fora da Ilha.

Junto com essa ocupação, estão presentes a contaminação química cotidiana inerente às atividades petrolíferas e os recorrentes "acidentes”, como são denominados pela indústria os crimes ambientais envolvendo derramamento de óleo, seus derivados e demais substâncias químicas em áreas de uso comum. Apesar da frequência e magnitude desses crimes ambientais, eles não têm gerado processos de indenização das comunidades afetadas nem uma fiscalização ambiental minimamente atuante por parte dos órgãos ambientais, de maneira a dissuadir a sua repetição. Diante desse quadro de desproporcional injunção de danos ambientais sobre um grupo social, as comunidades pesqueiras e quilombolas do Recôncavo, em especial, as mulheres da Ilha de Maré, compreendem que não apenas seus territórios de vida, mas também seus corpos se transformaram em uma grande zona de sacrifício do modelo de desenvolvimento hegemônico, baseado numa matriz energética centrada no uso de combustíveis fósseis.

Dialogando tanto com essa percepção das mulheres da Ilha de Maré quanto com o conceito proposto por Mbembe (2016), podemos afirmar que, hoje, uma

3. Para termos ideia da expressividade da ocupação desse território por comunidades de pesca artesanal, sublinhamos que há no Recôncavo, atualmente, 241 comunidades pesqueiras, das quais 54 se identificam como quilombolas, sendo 46 certificadas pela FCP (RIOS, 2017). 
necropolítica impera nesse território - uma política de morte que incide sobre determinados grupos ou populações inteiras a partir da aceitabilidade de se tirar a vida ou "deixar morrer", tendo como fundamento a raça e o racismo. Na mesma direção, Zagatto e Souza (2020, p. 264), ao tratar da situação da Ilha de Maré, propõem o conceito de "necropolítica ambiental”, visto que o modelo de desenvolvimento aí instalado vem "obrigando [as comunidades] a conviver de uma maneira perversamente sui generis com a experiência inexorável da morte”.

\section{As marisqueiras da Ilha de Maré: a construção do gênero na sua relação com o ambiente}

O campo de pesquisa sobre gênero compartilha do entendimento de que a divisão sexual do trabalho é uma dimensão estrutural que permeia as relações sociais, organizando-as por meio da hierarquia de gênero, que assume formas diferenciadas em função da classe e raça das mulheres (SAFFIOTI, 2013; BIROLI, 2018).

Na pesca artesanal, seguindo o padrão dominante da divisão sexual do trabalho, é sobre as mulheres que recai todo o trabalho relativo à reprodução social - atividades domésticas, cuidado com os filhos e idosos e apoio emocional a toda a família. De forma mais específica, na pesca artesanal, a divisão sexual do trabalho produtivo está associada a uma divisão espacial, ambas fortemente demarcadas e coproduzidas pela bipolaridade mar e terra - nesta última, também se inserem os ambientes de transição entre o mar e a terra.

Nesse universo, além de o mar e a terra representarem espaços físicos distintos, eles são dotados de uma enorme simbologia cultural, na qual a masculinidade está ligada ao primeiro e a feminilidade, ao segundo. É essa bipolaridade espacial que, em geral, define a divisão sexual do trabalho na pesca artesanal tanto no Brasil (ALENCAR, 1993) como em escala global (ALONSO-POBLACIÓN; NIEHOF, 2019). ${ }^{4}$

A partir da coleta de dados primários, por meio da observação direta do cotidiano das marisqueiras e de entrevistas semiestruturadas realizadas com $10 \mathrm{mu}$ lheres das comunidades de Porto dos Cavalos e Martelo, em agosto de 2018, identificamos, a dinâmica da vida cotidiana, no que se refere à divisão sexual e espacial do trabalho e ao acesso e controle de determinados espaços e recursos do ambiente. Em tais comunidades, como em outras da própria Ilha de Maré (RIOS, 2017), encontramos a bipolaridade espacial articulada à divisão sexual do trabalho, mas com particularidades, como descrevemos a seguir. Nelas, a atividade produtiva das

4. Encontramos exceções a esse padrão dominante em algumas comunidades do Brasil. No Recôncavo, em São Braz (MAIA, 2021) e na Ilha de Maré (RIOS,2017), por exemplo, alguns homens também mariscam. No entanto, a mariscagem é realizada majoritariamente por mulheres, seguindo a performance de gênero típica da pesca. 
mulheres se restringe aos ambientes de transição entre o mar e a terra, coroas e mangues, e à terra propriamente dita - ambiente onde elas também realizam as atividades reprodutivas, garantidoras da manutenção da vida de suas famílias.

As marisqueiras têm suas vidas cadenciadas pelo fenômeno da maré: a cada 15 dias, inicia-se uma marés, também chamada de maré grande, que dura cerca de uma semana, quando é possível mariscar nas coroas - afloramentos rochosos e/ou arenosos (Figura 2) que emergem durante a maré vazante no interior da BTS. Elas mariscam nas coroas localizadas no norte da comunidade, com o auxílio de pequenas canoas de fibra motorizadas ou com canoas a remo. Durante a maré, muitas delas vão para as coroas tanto na parte da manhã quanto à noite. Isso porque as marés são semidiurnas na plataforma continental da BTS, ou seja, há dois ciclos de marés de amplitudes semelhantes por dia, com intervalo de cerca de 12 horas entre eles. Na semana seguinte, terminada a maré grande, não há uma variação significativa da altura da água no interior da BTS, assim, as coroas ficam constantemente submersas (LESSA et al., 2009).

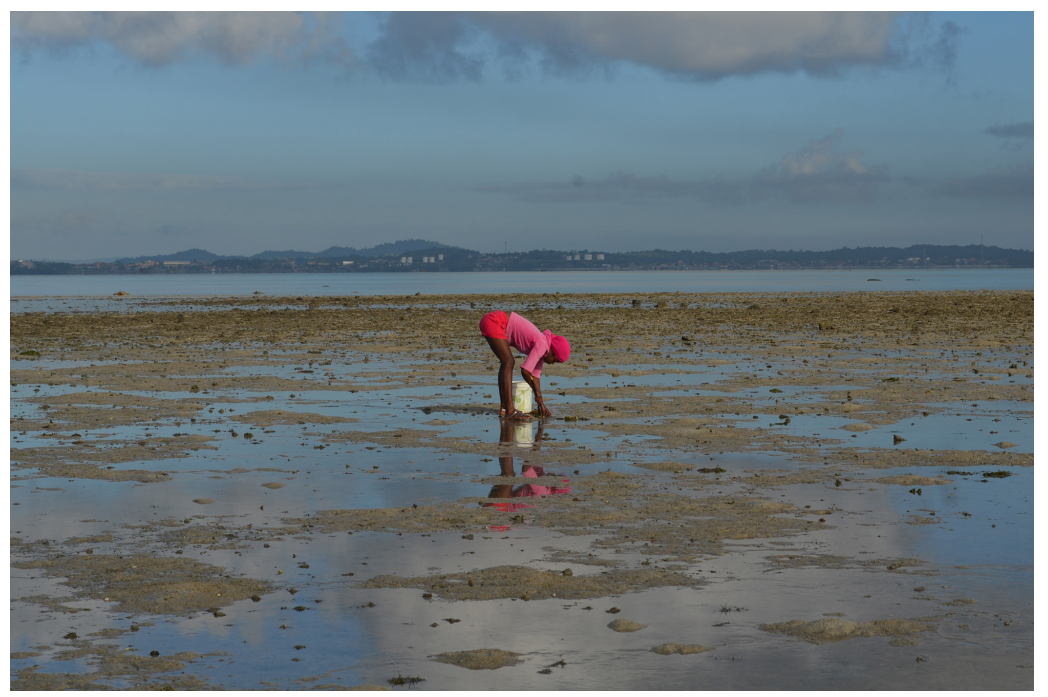

Figura 2. Coroa exposta na BTS

Fonte: Arquivo pessoal da autora, 2018.

Se observa que a paisagem marítima que encontramos no interior da BTS é bastante fluida, sendo sua dinâmica produzida pelos ciclos de maré: ora as coroas estão expostas, criando uma territorialidade de mariscagem, ora estão

5. As marisqueiras chamam de maré ou maré grande o período em que ocorre a maré sizígia, caracterizada por maiores amplitudes de maré durante o dia, ou seja, o mar avança e recua mais em relação à faixa de areia; há também uma maior amplitude na altura da água, permitindo o afloramento das coroas. 
submersas, compondo o território de pescadores artesanais com suas canoas e redes. Considerando isso, podemos afirmar que, apesar de as comunidades da tha de Maré se organizarem por meio da divisão sexual e espacial do trabalho, um mesmo lugar, a depender da maré, pode ter seu acesso e uso feito pelas mulheres ou pelos homens, o que, em certa medida, borra a bipolaridade espacial típica encontrada nas comunidades de pesca artesanal.

No período em que as coroas estão submersas, as marisqueiras recorrem, cada uma na frequência que lhe convém, ao manguezal para mariscar. No mangue, a mariscagem requer maior esforço físico: é preciso inserir o braço inteiro na lama à procura dos siris em suas tocas abaixo da superfície; ao andar, as pernas afundam, de forma tal que a atividade acaba exigindo que o corpo inteiro fique imerso na lama. Desse modo, a mariscagem nas coroas, quando estas estão expostas, é priorizada.

Nas coroas, a maioria das marisqueiras entrevistadas se concentra na captura de siris (Figura 3), pelo fato de o retorno financeiro ser mais significativo $\mathrm{R} \$ 25$ a $\mathrm{R} \$ 30,00 / \mathrm{kg}$, em agosto de 2018 . A cada ida à coroa, que dura cerca de quatro horas de mariscagem, capturam-se, em média, $2 \mathrm{~kg}$ de siri catado, o que equivale a 100 siris. A ostra tem um retorno financeiro semelhante ao do siri, mas, por apresentar uma arte de pesca mais trabalhosa (Figura 4), as mulheres se dedicam menos a essa atividade. O sarnambi (um molusco) tem retorno financeiro menor $\mathrm{R} \$ 20,00 / \mathrm{kg}$, em 2018 - e requer menos domínio de técnica, por esse motivo, jovens e crianças costumam exercer esse tipo de mariscagem. Mas, quando a conjuntura é de escassez (quando está fraco de siri, como dizem), as mulheres também partem para a coleta do sarnambi (Figura 5).

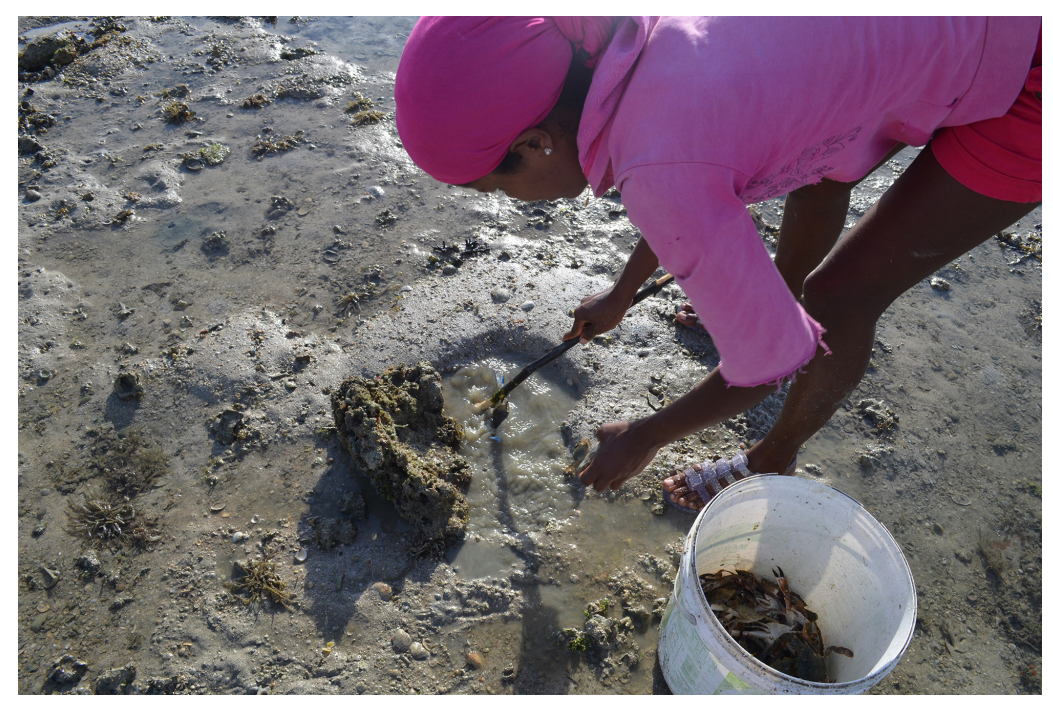

Figura 3. Mariscagem de siri

Fonte: Arquivo pessoal da autora, 2018. 


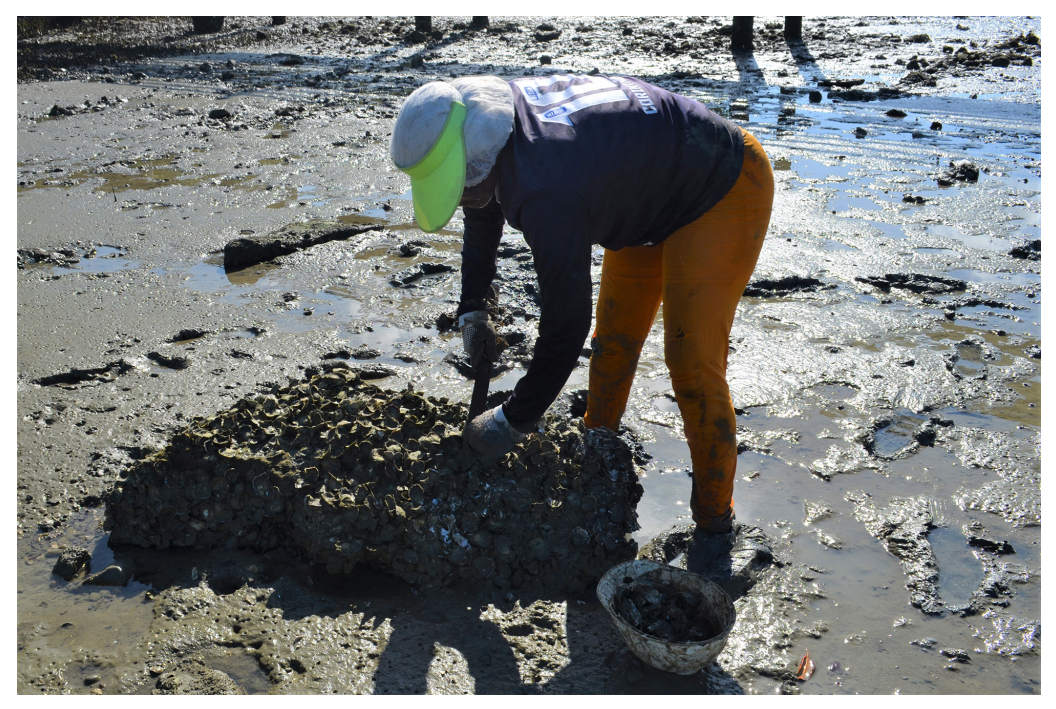

Figura 4. Mariscagem de ostra

Fonte: Arquivo pessoal da autora, 2018.

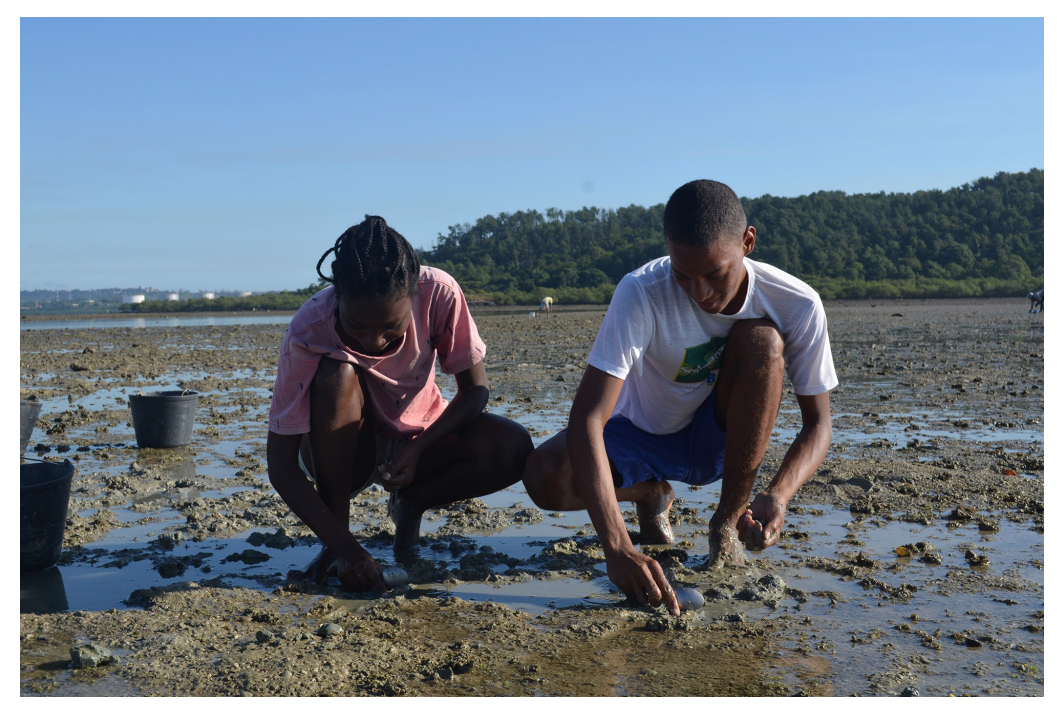

Figura 5. Mariscagem de sarnambi

Fonte: Arquivo pessoal da autora, 2018.

Ao retornar das coroas ou do mangue, elas dão início à segunda etapa das atividades: o beneficiamento, feito no quintal de suas casas. Com o uso de lenha e uma panela, cozinham o marisco e, em seguida, iniciam a catação, ou seja, a retirada da carne de dentro do siri e das conchas - sarnambis, ostra, sururu, tapu (Figura 6) -, acondicionando o material recolhido no freezer em sacos de $1 \mathrm{~kg}$. A catação é a etapa da produção a que as mulheres dedicam mais tempo no dia. Para cada quilo de siri catado (em média, 50 siris), as mulheres levam no mínimo duas horas no beneficiamento. Além disso, as marisqueiras casadas ou mães de jovens pescadores também 
catam o siri que seus maridos e filhos capturam com manzuá (tipo de armadilha) no mangue e estuários, uma vez que, na divisão sexual do trabalho na pesca, os homens não realizam essa atividade. Portanto, mesmo quando as mulheres não vão pessoalmente à coroa, estão às voltas com a atividade de catação de siri.

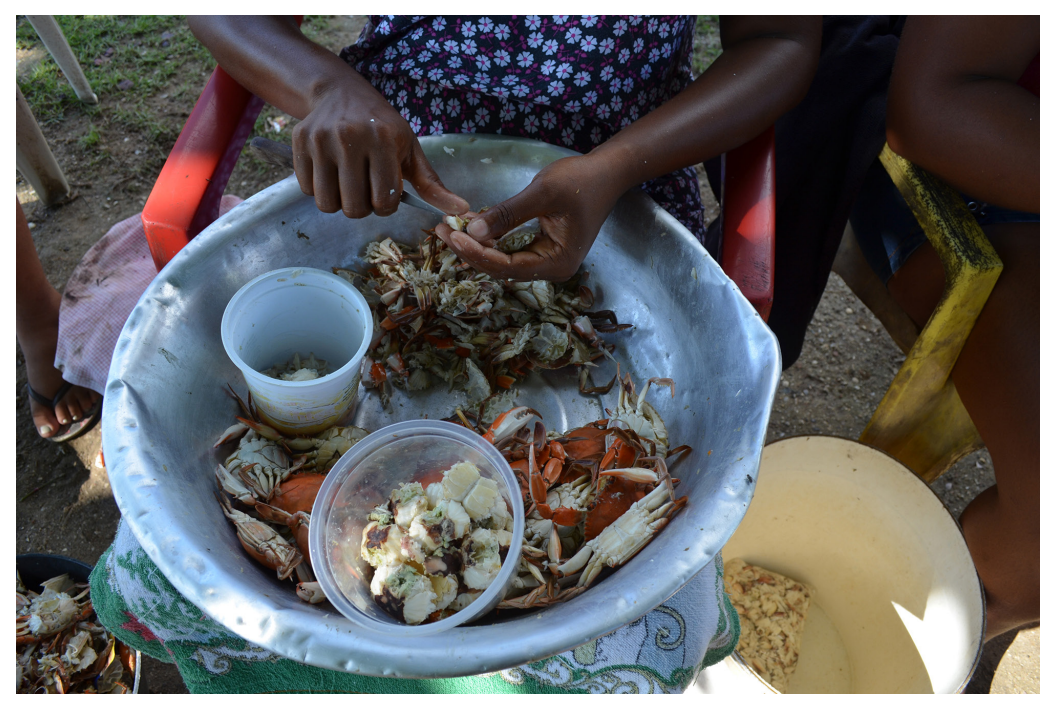

Figura 6. Marisqueira na catação de siri Fonte: Arquivo pessoal da autora, 2018.

Algumas mulheres também se envolvem com a etapa de comercialização. Assim, diante da enorme quantidade de afazeres cotidianos, elas buscam se organizar para realizar as atividades domésticas entre as etapas do beneficiamento. No entanto, no trabalho de campo, observamos que essas atividades acontecem com frequência de forma concomitante: enquanto a comida cozinha no fogão, a mulher cata siri no quintal e vigia a panela no fogão.

As mulheres organizam o cotidiano da seguinte maneira: acordam por volta das cinco e meia da manhã; as que têm filho pequeno preparam-no para ir à escola; fazem o café da manhã, às vezes, também preparam o almoço, quando dá tempo; vão para a maré, se for a semana de maré. Nesta última tarefa, ocupam-se de 4 a 6 horas, contando o tempo de deslocamento. Então, retornam à casa, cozinham o marisco, almoçam e já iniciam a catação de siri. Quando não vão à maré, catam siri o dia todo. Finalizam o dia de atividades entre 20 e 21 horas, dependendo da quantidade de siri para catar. Com efeito, as mulheres trabalham nas atividades produtivas ou reprodutivas de 12 a 16 horas ininterruptas por dia. Verônica, por exemplo, descreve sua rotina da seguinte forma: 
Normalmente, levanto antes de 6 horas. Preparo o menino para ir para escola e começo a fazer algumas coisas de casa. Coloco o siri no fogo, faço o almoço e na sequência começo a catar o siri ou vou para maré. [...] quando chego em casa da maré, começa a preparação para catar siri, tanto o que trouxe como o do marido que também pesca com manzuá; a ostra e sarnambi fica para o outro dia. No outro dia, cedo, cozinho o que catei no dia anterior (siri, ostra, sarnambi), largo o cozido em casa e vou de novo para maré. Quando venho de lá para cá, cato o que eu já cozinhei e largo o de hoje para o outro dia. Às vezes, cato o siri até 9:30-10:00h da noite. Mas normalmente vai até umas 7:30h da noite catando.

\section{As implicações do petróleo no território e nos corpos das marisqueiras}

Como já apontamos, tanto o território em terra, o espaço de moradia das comunidades, quanto o território marítimo são ocupados pela cadeia petrolífera, entre outras indústrias. Apesar de os poços terrestres de exploração de petróleo da Petrobras (Figura 7) estarem temporariamente abandonados ou $\operatorname{arrasados}^{6}$ (isto é, secos, sem presença de óleo e/ou gás), sem haver, portanto, exploração e produção de petróleo e gás há alguns anos na Ilha de Maré, suas estruturas se mantêm no território, perturbando a paisagem e a vida da comunidade e da biota.

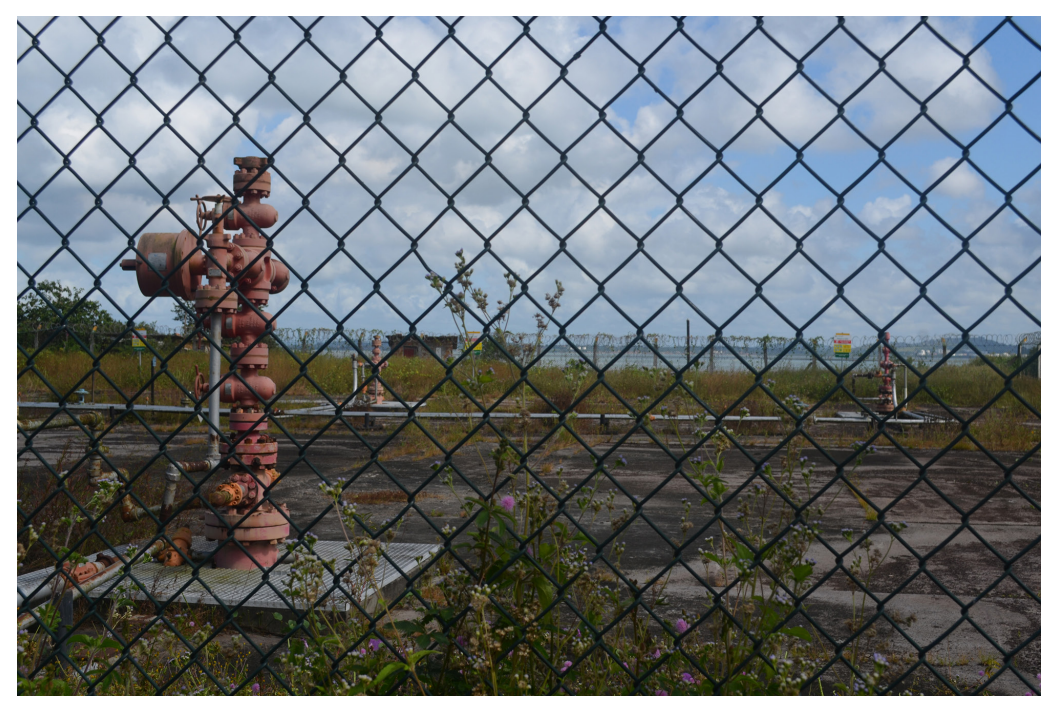

Figura 7. Poço de petróleo na comunidade do Martelo Fonte: Arquivo pessoal da autora, 2018.

As mulheres de Martelo e Porto dos Cavalos relatam que a presença dessas "infraestruturas petroleiras” (BUTI, 2020) gera um forte sentimento de insegurança

6. Terminologia utilizada pela Petrobras para caracterizar a atual situação dos poços. 
e medo, principalmente em relação ao bem-estar de seus filhos. Até poucos anos atrás, os poços não eram cercados por grades; por não haver estruturas de lazer na comunidade, eles se transformavam em espaços de brincar pelas crianças. Atualmente estão cercados, como resultado de forte mobilização da população; porém, muitas vezes, o portão que leva à área fica aberto e as crianças acabam tendo acesso a tais estruturas. A simples presença dessas infraestruturas petroleiras no território quilombola afeta a tranquilidade e a saúde mental das mulheres que são mães, como nos relata Veronica, na época, mãe de um menino de 10 anos:

Quando o menino sai para brincar, fico apreensiva em saber que de repente ele tá nesse local que não pode ir, mas tem criança que, por mais que a gente fale e controle, eles vão para aquele local. Porque, mesmo que agora está cercado, ainda tem criança que anda por ali, então eu fico com medo de saber se ele está subindo ali, até porque tem lugares ao redor que ficam com água empoçada, não sabemos se ele está exposto a pegar alguma doença.

Elas, ainda, destacam a insegurança em mariscar nas áreas de mangue localizadas nas adjacências de tais poços, dado seu histórico de vazamentos de petróleo bruto e despejo de rejeitos pela Petrobras. Como denuncia Jassiara:

Quando a Petrobras chegou, destruiu muito mangue, o petróleo começou a matar os mariscos, a gente encontrava as ostras e sururus tudo aberto... o óleo vazava direto na época da construção. Tinha um viveiro [no mangue] que dava muito peixe e siri no Martelo, a Petrobras matou... Morreu muito mangue, e só depois de muitos anos que deu uma recuperada, mas não ficou igual como era.

Esses relatos nos informam que áreas de mangue localizadas na própria comunidade e historicamente utilizadas pelas mulheres para mariscar nos períodos entre marés se transformaram em ambientes ocupados e perturbados pelo petróleo. Portanto, áreas que eram tidas como de fácil acesso para as marisqueiras de Porto dos Cavalos e Martelo se tornaram áreas contaminadas e inapropriadas para a atividade produtiva característica do local. 0 efeito direto para essas mulheres foi a redução do território de mariscagem e a imposição do deslocamento para áreas de mangues mais distantes das casas, aumentando, assim, o tempo envolvido nessa atividade. Algumas mulheres, no entanto, ainda mariscam nessas áreas, colocando, de forma mais direta, a sua saúde em risco.

O relato de Jassiara sobre a presença de óleo no mangue resultante de vazamentos antigos coincide com um episódio ocorrido na comunidade quilombola de Dom João, também localizada no Recôncavo e ocupada pela cadeia petrolífera. 
Buti (2020) narra o encontro no manguezal de um pescador com o que chamou de "guaiamum petroleiro": "um guaiamum de coloração preta, com uma consistência oleaginosa e um cheiro bastante forte, fruto da contaminação por petróleo na área ao fundo do buraco onde o animal morava, com profundidade em torno de 2 metros" (BUTI, 2020, p. 285). Segundo o pescador, o petróleo que estava no fundo do buraco onde vivia o "guaiamum petroleiro" era oriundo de um vazamento ocorrido há décadas. Isso evidencia a longa duração da perturbação do petróleo no território de vida dessas comunidades e seus efeitos sobre os corpos dos animais e, eventualmente, sobre os corpos das mulheres.

Para além da contaminação do espaço e dos recursos, dos quais as comunidades dependem para sua reprodução material, há todo um universo cosmológico na relação profunda que as mulheres e seus corpos estabelecem com os mangues, coroas e águas perturbados pela cadeia petrolífera. A fala de Eliete Paraguassu, umas das lideranças da Ilha de Maré e moradora de Porto dos Cavalos, expressa bem a violência que a lógica de desenvolvimento exerce sobre o universo cósmico e espiritual das mulheres:

Eles destroem o mangue que é um espaço sagrado para gente, para além de ser o espaço de onde a gente tira o alimento dos nossos filhos. A gente tem uma relação profunda com o mangue, de respeito e de amor... é a casa de $\operatorname{Nana\tilde {}}^{7}$ [...]. A gente sente uma dor profunda quando vê o mangue e as coroas sujos de petróleo ou destruídos, é como se tirassem um pedaço da gente.

O mangue localizado na comunidade do Martelo não é o único espaço perturbado pelo petróleo nem é somente ele que coloca em risco o modo de vida e a saúde das marisqueiras. Como descrevemos, a BTS se transformou em um território amplamente ocupado e apropriado pela cadeia petrolífera, o que produziu um cenário de intensa contaminação química do ar, dos sedimentos, da água, acumulando-se ao longo da cadeia alimentar marinha (HATJE et al., 2009). Aqui, o marcador de modo de vida ligado ao meio ambiente se revela de extrema relevância para a experiência vivida pelas mulheres, pois, sendo seu modo de viver e produzir indissociável de sua relação com o meio ambiente, os efeitos nocivos da degradação de seus territórios de trabalho e vida são sentidos diretamente em seus corpos e saúde. Vale assinalar também que, por ficarem muitas horas em contato direto com o sedimento ao mariscar nas coroas e nos mangues, a contaminação por contato dérmico é muito maior nas mulheres que nos homens, os quais pescam em

7. Orixá feminino, divindade do candomblé e de outras religiões de matriz africana. 
seus barcos, apesar de também se contaminarem pelo ar, por contato com a água e pela alimentação. A fala de Eliete Paraguassu é categórica a respeito disso: "Nós somos as mais contaminadas, são nossos corpos que estão na lama”.

Portanto, na percepção dessas mulheres, devido à divisão sexual e espacial do trabalho, no atual cenário de contaminação, a saúde física delas é mais afetada que a dos homens, principalmente a saúde reprodutiva. Como observa Veronica:

\footnotetext{
O que eu sei de problema de saúde é que a maioria das mulheres quando fazem o preventivo, a médica identifica que estamos com inflamação, e fala para a gente se afastar da lama. Isso é o que a gente sabe porque fazemos o exame, mas com certeza devemos ter outras coisas que não sabemos, porque a gente não faz exames mais aprofundados de sangue, de pele.
}

A percepção e o medo da contaminação do ambiente, dos animais e, consequentemente, dos corpos dos homens, mulheres e crianças quilombolas se tornaram uma realidade ainda mais tangível para as marisqueiras da Ilha de Maré após a investigação realizada pela professora Neuza Maria Miranda dos Santos, da Escola de Nutrição da Universidade Federal da Bahia (UFBA). A pesquisa, realizada em 2005, teve como objetivo verificar o nível de contaminação por cádmio e chumbo em 117 crianças da Ilha de Maré com idade de até 6 anos, um universo de 50\% das crianças do local na época (ZAGATTO; SOUZA, 2020). Os resultados foram alarmantes, como Neuza Miranda relatou ao Mídia Ninja (ASSASSINO INVISÍVEL, 2019): "90\% das crianças estão contaminadas com mais de 10 microgramas de chumbo por decilitro de sangue, acima do preconizado pela Organização mundial da saúde”. E continua: "em Bananeiras encontrei no sangue delas níveis elevados de cádmio [sic] metal considerado carcinogênico para o ser humano, também encontrei o pescado contaminado, marisco e peixes, com os mesmos metais chumbo e cádmio".

O resultado desse estudo pode ser considerado um ponto de inflexão na vida e luta das mulheres da Ilha de Maré. Foi aí que tiveram, em parte, dimensão da gravidade da contaminação química a que elas e seus filhos estavam submetidos - afirmamos "em parte” porque outros contaminantes, como os hidrocarbonetos, não foram estudados. Tal resultado, associado à plena consciência da dificuldade de reversão desse cenário devastador, o qual só se aprofunda com a permanência das atividades petrolíferas e industriais no entorno do território, tem gerado, desde então, um grande sofrimento social e psicológico nas mulheres da Ilha de Maré: o medo de que seus filhos desenvolvam alguma doença fatal como o câncer se faz cada vez mais presente no imaginário delas.

Na Ilha de Maré, são muitos os relatos sobre a incidência de câncer em crianças e jovens. Uma mãe, ao nos falar sobre a perda de sua filha Adriane aos 13 anos 
de idade, em decorrência de um câncer, declarou: "Câncer antigamente era raro, a gente nem tinha ouvido falar, agora cada vez a gente sabe de mais jovens com câncer, perdi minha menina assim”. Sobre isso, Marizelha Lopes, marisqueira e uma das lideranças da Ilha de Maré, na reportagem Assassino Invisível (2019), afirma:

[...] quando a gente perde a Adriane, aí diminui a esperança da gente para que a geração futura esteja garantida.

[...]

A gente, por exemplo, nunca ouviu falar em cádmio, em chumbo, em mercúrio; a gente nunca ouviu falar em propeno, em butieno [sic], acetona... a gente nunca tinha ouvido falar nisso. Então, essas coisas não é [sic] nossas. O pai conta que meu bisavô, o vô Candido, quando viu o Porto de Aratu chegar ele dizia "acabou a vida da gente, acabou a saúde da gente”. E vô Candido estava certo, porque tem diminuído muito a vida da gente, o tempo de vida da gente.

A elevada incidência de câncer nos jovens se explica pelo fato de crianças serem mais vulneráveis à exposição de substâncias químicas presentes no ambiente que adultos, pois têm maior dificuldade em metabolizá-las. Em casos de exposição continuada ou crônica, há o acúmulo dessas substâncias em órgãos, ossos e células adiposas, podendo levar, anos depois, ao desenvolvimento de câncer, entre outros problemas de saúde (MELLO-DA-SILVA; FRUCHTENGARTEN, 2005).

Tal sofrimento, paradoxalmente, tem impulsionado e fortalecido a luta das mulheres contra o racismo ambiental. Segundo Eliete Paraguassu, muitas mulheres, e ela própria, cuja filha foi uma das crianças que participaram dos estudos de Neuza Miranda, passaram a se envolver de forma mais efetiva na luta após tal pesquisa, o que revela como a maternidade pode se transformar em uma força potente na direção do enfrentamento contra as injustiças ambientais, quando a saúde e o bem-estar dos filhos estão em risco.

Apesar de a pesquisa ainda não ter sido publicada, as mulheres lideranças da Ilha de Maré se apropriaram dos resultados, como assinalam Zagato e Souza (2020). Elas passaram a divulgá-los nos espaços públicos que ocupam e a exigir dos órgãos públicos melhorias nas políticas de saúde e ampliação da pesquisa para a população adulta, com a inclusão dos demais contaminantes. Essa é uma demanda recorrente das mulheres, deixando claro como a ocupação do território pela cadeia petrolífera as mantém em constante estado de alerta e de preocupação, algo que gera muita ansiedade, angústia e sofrimento, pois elas sabem que estão contaminadas, mas não sabem com quais substâncias químicas, qual o nível da contaminação, quais doenças podem desenvolver e o que devem fazer para minimizar a contaminação em seus próprios corpos e no de seus filhos. Trata-se de um estado de incerteza e preocupação cotidiana que afeta profundamente a saúde mental das mulheres. 


\section{Interseccionalidade em interface com um território ambientalmente degradado}

Como apresentamos, o território de vida e de reprodução social e material das mulheres da Ilha de Maré se transformou em um território ambientalmente degradado. Aqui nos interessa compreender como se dá a interação entre esse território - zona de conflito ambiental entre as comunidades afetadas e as atividades petrolíferas - com os múltiplos padrões de opressão aos quais as mulheres são submetidas, afetando e transformando a experiência de vida delas.

O cenário descrito anteriormente se agrava ainda mais quando é cruzado com as condições de precariedade dos serviços públicos presentes no território, entre eles, os problemas de esgotamento sanitário e a dificuldade de acesso aos serviços de saúde. Posto que a Ilha de Maré é o bairro mais negro de Salvador e que também se configura como um bairro de baixa renda, seguindo o padrão de associação entre recorte racial e de classe do restante do país, sustentamos que a articulação da categoria raça com a de classe é determinante para tal precariedade no território, o que, por sua vez, revela o racismo institucional ${ }^{8}$ que atravessa os modos como entes federativos implementam políticas do Sistema Único de Saúde do país - ocorrência mais acentuada em territórios remotos, como o da Ilha de Maré.

A ausência de esgotamento sanitário na Ilha de Maré9 não é uma realidade exclusiva dessas comunidades. Uma considerável parcela da população negra brasileira convive com a precariedade do saneamento ambiental, em particular, do esgotamento sanitário. Isso tem produzido taxas de adoecimento e mortalidade desproporcionalmente altas em crianças e idosos negros por doenças relacionadas ao saneamento ambiental inadequado (JESUS, 2020). Rios (2017) relata que na Ilha de Maré

os esgotos a céu aberto têm atraído insetos e causado doenças em várias crianças e adultos. Além do mau cheiro, o despejo dos resíduos tem contaminado os manguezais e as águas e ocasionado problemas de pele e outras doenças nos pescadores e marisqueiras. (RIOS, 2017, p. 303)

Em relação aos serviços de saúde, existe somente um posto de saúde na Ilha de Maré, construído em 2009, após ampla mobilização da população.

\footnotetext{
8. O racismo institucional é resultante do funcionamento das instituições que atuam em uma dinâmica que confere, ainda que indireta e não intencionalmente, desvantagens e privilégios a indivíduos e coletividades, de acordo com seu pertencimento racial. Cf. ALMEIDA, S. L. de. O que é racismo estrutural? Belo Horizonte: Letramento, 2018.

9. Apesar de o abastecimento de água atender 95\% dos domicílios, apenas 4,2\% deles possuem esgotamento sanitário, os demais despejam seus dejetos diretamente nos mangues, rios ou mar (IBGE, 2010).
} 
Ele está inserido na comunidade Praia Grande, mais de uma hora de caminhada da comunidade de Porto dos Cavalos e Martelo. Não funciona 24 horas por dia e conta apenas com atendimento ambulatorial, sem instalação hospitalar. Além disso, as mulheres reclamam que não há nenhum tipo de atendimento para prevenção de doenças relacionadas à contaminação química no território, a fatores genéticos da população negra como anemia falciforme, hipertensão arterial e diabetes mellitus, nem tratamento fisioterapêutico. Dada as características da ocupação das mulheres, a oferta desse tratamento é de fundamental importância para sua saúde e qualidade de vida.

A precarização do acesso a serviços de saúde pela população negra também tem sido documentada e faz parte de um conjunto do que tem sido chamado de iniquidades raciais em saúde (FAUSTINO, 2012; WERNECK, 2016). Em relação às mulheres, as iniquidades raciais se fazem presentes desde a ausência de uma área específica de conhecimento e produção científica acerca da saúde da mulher negra - apesar de ser sabido que esse grupo possui questões de saúde próprias -, passando pelo acesso precarizado ao SUS, tanto no estágio de prevenção quanto no de tratamento, como é a realidade na Ilha de Maré. E ainda: quando se tem acesso ao SUS, ele é permeado por discriminação racial (WERNECK, 2016). Portanto, a discriminação com base em gênero e raça atuam conjuntamente.

Já no que se refere à ocupação das mulheres marisqueiras, há uma grande lacuna na produção de conhecimento sobre doenças laborais associadas à mariscagem. De acordo com seus relatos, frequentemente, o Instituto Nacional do Seguro Social (INSS) lhes oferece um tratamento discriminatório, negando-lhes, muitas vezes, o direito à licença médica, solicitada em razão de lesões no trabalho, as quais acometem grande parte das trabalhadoras da Ilha de Maré, como verificamos durante a pesquisa. Todas as entrevistadas disseram sentir fortes dores na coluna e/ ou nos membros superiores, havendo casos de marisqueiras novas impossibilitadas de catar mariscos, dada a gravidade de suas lesões.

De forma pioneira, Paulo Pena e Vera Martins coordenaram um projeto de pesquisa sobre doenças e acidentes de trabalho nas atividades de mariscagem na Ilha de Maré, que se estendeu para outras comunidades pesqueiras da Bahia. Os resultados foram contundentes. Como eles apontam:

Em 2007, o relatório de pesquisa divulgado foi contundente quanto à diversidade e a gravidade de riscos ocupacionais presentes no cotidiano do trabalho das marisqueiras. Além da exposição aos riscos conhecidos, chamou a atenção o ritmo acelerado de trabalho com excessiva carga de movimentos com esforços repetitivos associados ao desenvolvimento de Lesões por Esforços Repetitivos ou LER. Da análise ergonômica realizada, além de outras condições, verificou-se 
que havia cadências infernais em várias atividades de extração de mariscos, com número de movimentos nas extremidades dos membros superiores podendo alcançar a média de 10 mil movimentos por hora, equivalente ao encontrado nas funções de digitação nos serviços modernos. A cata de determinados mariscos, as posturas tradicionais, a retirada das conchas, dentre outras atividades estavam associadas a queixas comuns de dores, muitas vezes insuportáveis, edemas, deformidades, dormências e perda de capacidade funcional dos membros superiores. (PENA; MARTINS, 2014, p. 20)

Posto isso, compreendemos que, no contexto específico das comunidades aqui estudadas, a interação entre a interseccionalidade das categorias de gênero, classe, raça e modo de vida ligado ao meio ambiente com o território degradado, apropriado e contaminado pela cadeia petrolífera confere às mulheres marisqueiras uma sobrecarga de trabalho e um grave cenário de adoecimento físico e mental.

A interseccionalidade entre os eixos de opressão gênero, classe e raça acontece da seguinte forma: a relação e a hierarquia de gênero, por meio da divisão sexual e espacial do trabalho, definem os espaços e os recursos do ambiente que podem ser acessados pelas marisqueiras, assim como lhes conferem toda a responsabilidade pelo trabalho reprodutivo e pela parcela mais penosa do trabalho produtivo exercido por elas e pelos seus cônjuges. Este último, ao se articular com o baixo valor de troca atribuído ao produto da mariscagem, ou seja, ao pequeno retorno financeiro que as mulheres obtêm decorrente de sua ocupação socialmente desvalorizada, lhes impõe muitas horas ininterruptas de trabalho diário para obtenção de um retorno maior, com base no volume produzido. Tal processo vem gerando o grave cenário de adoecimento relatado (PENA; MARTINS, 2014), situação agravada pela precariedade do acesso ao SUS e dos tratamentos ofertados, em associação ao racismo institucional e à conduta discriminatória oferecida pelo INSS às marisqueiras. Outro cruzamento desses eixos se dá por meio do racismo institucional, que permite a naturalização da ausência de esgotamento sanitário na ilha por parte das agências de água e esgoto. Isso aumenta o adoecimento e a morbimortalidade de crianças e idosos, algo que, diante da hierarquia de gênero, sobrecarrega ainda mais as mulheres em razão do cuidado que precisam ofertar a enfermos da família e da comunidade.

Ademais, o marcador modo de vida ligado ao meio ambiente impõe às comunidades de pesca artesanal um contato maior de seus corpos com o meio ambiente contaminado - aspecto que, somado a uma alimentação baseada nos produtos oriundos da atividade extrativista, os quais também podem estar contaminados, pode gerar graves efeitos na saúde. No entanto, essa dolorosa realidade de contaminação química e adoecimento, ainda que afete toda a comunidade, atinge de forma 
diferenciada certas pessoas, conforme o gênero e a idade. Como já apontamos, em função da atividade produtiva, as mulheres são mais afetadas que os homens, além de recair sobre a exclusiva responsabilidade delas o cuidado de jovens e crianças adoecidos. Por fim, a contaminação química tem gerado um efeito desestabilizante na saúde mental das mulheres, dado que estas têm pleno conhecimento da transformação de seu território de vida em um território contaminado, zona de sacrífico do capital, que adoece e leva a óbito seus filhos. Ao mesmo tempo, as mulheres encontram grandes dificuldades para reverter esse quadro de violações de direito.

Entretanto, é importante não perder de vista que a mesma interseccionalidade responsável por impor maior vulnerabilidade social das mulheres negras, de classe socialmente desfavorecida e pertencentes a comunidades com modo de vida ligado ao meio ambiente, também tem um efeito mobilizador, potencializando a agência e resistência delas em todo território da América Latina (SVAMPA, 2019). Na Ilha de Maré, as mulheres têm ocupado o espaço público e estão na linha de frente no enfrentamento contra as empresas e a omissão do Estado, protagonizando a resistência na luta pelo direito ao território e à vida, tanto delas mesmas quanto de seus filhos, companheiros e comunidade como um todo. Para essas mulheres, a alternativa que se apresenta é a luta contra o modelo de desenvolvimento, o racismo e a necropolítica, em defesa de seu modo de vida. Nas palavras de Eliete Paraguassu:

Nós vivemos uma guerra silenciosa contra um monstro invisível, que
é a contaminação química, imposto por esse modelo de desenvolvi-
mento que é perverso e assassino [...] é contra esse racismo ambien-
tal que nos adoece, que contamina nossos corpos, principalmente o
das mulheres, que a gente luta [...] [a luta] é pela garantia de direitos
e em defesa do nosso território.

Podemos afirmar, pois, que o presente trabalho se configura como um exercício que busca entender como um modelo de desenvolvimento ancorado numa matriz energética altamente dependente de combustíveis fósseis e gerador de uma série de conflitos ambientais tem afetado e vulnerabilizado, de forma mais profunda, a vida das mulheres negras com modo de vida ligado ao meio ambiente, como é o caso das marisqueiras da Ilha de Maré.

Esperamos que ele incentive futuras pesquisas no campo dos conflitos ambientais no Brasil a inserir o gênero e a raça no centro de suas análises por meio de uma abordagem interseccional - já que os corpos mais afetados por esse modelo de desenvolvimento têm gênero, cor, e classe -, contribuindo, assim, para o crescimento do incipiente campo da Ecologia Política Feminista latino-americana. 


\section{Referências}

ACSELRAD, H. As práticas espaciais e o campo dos conflitos ambientais. In: (Org.). Conflitos Ambientais no Brasil. Rio de Janeiro: Relume Dumará, 2004. p. 13-35.

ALENCAR, E. Gênero e trabalho nas sociedades pesqueiras. In: FURTADO, L. G.; LEITÃO, W.; FIÚZA, A. M. de (Orgs.). Povos das águas: realidades e perspectivas na Amazônia. Belém: MPEG, 1993, p. 63-81.

ALONSO POBLACIÓN, E.; NIEHOF, A. On the power of a spatial metaphor: Is female to land as male is to sea? Maritime Studies, v. 18, n. 3, 2019, p. 249-257.

ASSASSINO INVISÍVEL: lixo industrial na Ilha de Maré chega a níveis mortais. Mídia Ninja, 31 de março de 2019. Reportagem e vídeo (5:50 min.) Disponível em: https://midianinja. org/news/ /assassino-invisivel-lixo-industrial-na-ilha-de-mare-chega-a-niveis-mortais/. Acesso em: 12 set. 2020.

BAIRROS, L. Nossos Feminismos Revisitados. Revista Estudos Feministas, Florianópolis, ano 3, n. 2, 1995, p. 458-463.

BARCELlOS, G. H. Desterritorialização e R-existência Tupiniquim: mulheres indígenas e o complexo agroindustrial da Aracruz celulose. 2008. 424 f. Tese (Doutorado em Geografia). Universidade Federal de Minas Gerais, Belo Horizonte, 2008.

BARICKMAN, B. J. Até a véspera: O trabalho escravo e a produção de açúcar nos engenhos do Recôncavo baiano (1850-1881). Afro-Ásia, n. 21-22, 1998-1999, p. 177-238.

BIROLI, F. Gênero e desigualdades: limites da democracia no Brasil. 1 ed. São Paulo: Boitempo. 2018.

BUTI, R. P. Imagens do Petroceno: habitabilidade e resistência quilombola nas infraestruturas do petróleo em manguezais do Recôncavo baiano. Amazônica - Revista de Antropologia. v. 12, n. 1, 2020, p. 277-301.

COLLINS, P. H. Black Feminist Thought: Knowledge, Consciousness, and the Politics of Empowerment. 2 edition. New York: Routledge, 2000.

COMISSÃO PASTORAL DA PESCA. Relatório Conflitos Socioambientais e Violações de Direitos Humanos em Comunidades Tradicionais Pesqueiras no Brasil. 2016.

CRENSHAW, K. Documento para o encontro de especialistas em aspectos da discriminação racial relativos ao gênero. Estudos Feministas. Florianópolis, v. 10, n. 1, jan., 2002. p. 171-188.

ELMHIRST, R. Feminist Politic Ecology. In: PERREAULT, T.; BRIDGE, G.; MC CARTHY, J. (edits). Handbook of Political Ecology. New York: The Routledge, p. 519-540, 2015.

Ecologias políticas feministas: perspectivas situadas y abordajes emergentes. Ecologia Política. Cuadernos de debate internacional. Edição Especial Ecofeminismos e Ecologias Políticas y Ecologias Políticas Feministas. n. 54, 2018, p. 52-59.

FAUSTINO, D. M. A equidade racial nas políticas de saúde. In: BATISTA, L. E.; WERNECK, J.; LOPES, F. (orgs.). Saúde da População Negra. 2. ed. Brasília, DF: ABPN, 2012. p. 92-121. 
FAUSTINO, D. M.; FURTADO, F. Indústria do petróleo e conflitos ambientais na Baía de Guanabara: o caso do Comperj. Rio de Janeiro: Plataforma Dhesca, 2013a.

Mineração e violações de direitos: o projeto Ferro Carajás S11D, da Vale S.A. Açailândia: Plataforma Dhesca, 2013b.

FRAGA FILHO, W. Encruzilhadas da liberdade: histórias de escravos e libertos na Bahia (18701910). 2004. Tese (Doutorado em História). Campinas/SP: Unicamp, 2004.

FURTADO, F. Nem nossos corpos, nem nossos territórios: mulheres, desenvolvimento e conflitos ambientais. GT o6 Conflitos e Desastres ambientais: violação de direitos, resistência e produção do conhecimento. $42^{\circ}$ Encontro Anual da ANPOCS. Caxambu, 2018. 28f.

GARCIA, P. B.; CUEVAS, A. S. Una ecología política feminista en construcción: El caso de las "Mujeres de zonas de sacrificio en resistencia”, Región de Valparaíso, Chile. Psicoperspectivas, v. 16, n. 2, 2017, p. 33-42.

GONZALES, L. Racismo e Sexismo na Cultura Brasileira. Revista Ciências Sociais Hoje, ANPOCS, 1984, p. 223 -244.

IBGE. Instituto Brasileiro de Geografia e Estatística. Censo demográfico 2010. Disponível em: http://www.cens02010.ibge.gov.br. Acesso em: 01 jun. 2020.

INCRA. Instituto Nacional de Colonização e Reforma Agrária. Superintendência Regional da Bahia. Relatório Técnico de Identificação e Delimitação da comunidade Quilombola de Ilha de Maré. Salvador, Bahia, 2016.

INESC. Instituto de Estudos Socioeconômicos. Mulheres Amazônidas: a defesa dos territórios em tempos de crise. Brasília, 2020.

PACS. Instituto Políticas Alternativas para o Cone Sul. Mulheres e conflitos ambientais: nem nossos corpos nem nossos territórios- da invisibilidade à resistência. Rio de Janeiro: PACS, 2017.

HATJE, V. et al. Contaminação Química In: HATJE, V., ANDRADE, J. (orgs.). Baía de Todos os Santos: Aspectos oceanográficos. Salvador: EDUFBA, 2009. p. 243- 297.

JESUS, V. de. Racializando o olhar (sociológico) sobre a saúde ambiental em saneamento da população negra: um continuum colonial chamado racismo ambiental. Saúde e Sociedade, São Paulo. v. 29, n. 2, 2020, e180519.

LESSA, G. C. et al. Oceanografia Física. In: HATJE, V., ANDRADE, J. (orgs.). Baía de Todos os Santos: Aspectos oceanográficos. Salvador: EDUFBA, 2009. p. 71-119.

MAB. Movimento dos Atingidos por Barragens. O modelo energético e a violação dos direitos humanos na vida das mulheres atingidas por barragens. 34p. 2011.

MAIA, S. Neoliberalismo global, capitalismo racial e organização política de mulheres numa comunidade pesqueira quilombola do Recôncavo da Bahia. Latin American Research Review, v. 56, n. 2, 2021, p. 1-14. doi: 10.25222/larr.628.

MANESCHY, M. C.; SIQUEIRA, D.; ÁLVARES, M. L. M. Pescadoras: subordinação de gênero e empoderamento. Revista Estudos Feministas, Florianópolis, v. 20, n. 3, 2012, p. 713-737. 
MBEMBE, A. Necropolítica. Artes; Ensaios. Revista do Programa de Pós-Graduação em Artes Visuais EBA/UFRJ, n. 32, 2016, p.121-153.

MELLO, C. C. A. As vítimas dos desastres ambientais no Brasil têm cor e ela não é branca. [online] 2015. 2p. Disponível em: https://plataformapoliticasocial.com.br/as-vitimas-dos-desastres-ambientais-no-brasil-tem-cor-e-ela-nao-e-branca/. Acesso em: 12 set. 2020.

MELLO-DA-SILVA, C. A.; FRUCHTENGARTEN, L. Riscos químicos ambientais à saúde da criança. Jornal de Pediatria, Rio de Janeiro. n. 81 (5 Supl), 2005, p. S205-S211.

MOLLET, S.; FARIA, C. Messing with gender in feminist political ecology. Geoforum, n. 45, 2013, p. 116-125.

OBTEIA. Observatório de Políticas Pública Integral das Populações do Campo, da Floresta e das Águas. Análise de Contexto, Ilha de Maré, Salvador (BA). 2014. 23p.

OYARZÚN, E. A.; ALVAREZ, A. Z. Apuntes iniciales para la construcción de una Ecología Política Feminista de y desde Latinoamérica. Polis, Revista Latinoamericana, n. 54, 2019, p. $12-26$.

PENA, P. G. L.; MARTINS, V. L. A. Introdução. In: (orgs.). Sofrimento Negligenciado: doenças do trabalho em marisqueiras e pescadores artesanais. Salvador: EDUFBA, 2014. p. 17-27.

PoEMAS. Antes fosse mais leve a carga: avaliação dos aspectos econômicos, políticos e sociais do desastre da Samarco/Vale/BHP em Mariana (MG). Relatório. Belo Horizonte, Dezembro de 2015. 10op.

RIOS, K. A. N. A questão da luta na/pela terra e água dos pescadores artesanais: Desafios e perspectivas do processo de regularização dos territórios pesqueiros de Ilha de Maré (BA) 2017. Tese (Doutorado em Geografia). Salvador: Universidade Federal da Bahia, 2017.

SAFFIOTI, H. A mulher na sociedade de classes: mito e realidade. São Paulo: Expressão Popular, 3. ed., 2013, 528p.

SOUZA, S. R.; RIBEIRO, N. S.; MARTINEZ, S. A. Mulheres em comunidades pesqueiras no Brasil: um balanço da produção em teses e dissertações (2007-2017). In: MARTINEZ, S. A.; HELLEBRANT, L. (orgs.). Mulheres na atividade pesqueira no Brasil. Campo dos Goytacazes: EDUENF, 2019, p. 23-52.

SVAMPA, M. As fronteiras do neoextrativismo na América Latina: Conflitos socioambientais, giro ecoterritorial e novas dependências. São Paulo: Editora Elefante, 2019, 192p.

WALTER, T. et al. Conflitos ambientais envolvendo pescadores (as) artesanais na zona costeira. In: MARTINEZ, S. A.; HELLEBRANT, L. (orgs.). Mulheres na atividade pesqueira no Brasil. Campo dos Goytacazes: EDUENF, 2019. p. 77-112.

WERNECK, J. Racismo institucional e saúde da população negra. Saúde e Sociedade, São Paulo. v. 25, n. 3, 2016, p. 535-549.

ZAGATTO, B. P.; SOUZA, L.E.V. A necropolítica ambiental nos quilombos de Ilha de Maré, Bahia, Brasil. Amazônica - Revista de Antropologia. v. 12, n. 1, 2020, p. 253-276. 


\section{Patricia Rodin}

Bióloga pela Universidade Federal do Rio de Janeiro (UFRJ), mestra em Ecologia pela Universidade de Brasília (UnB) e doutoranda em Planejamento Urbano e Regional pelo Instituto de Pesquisa e Planejamento Urbano e Regional da Universidade Federal do Rio de Janeiro (IPPUR/UFRJ). É, desde 2009, analista ambiental do Instituto Brasileiro do Meio Ambiente e dos Recursos Naturais Renováveis (IBAMA), Coordenação de licenciamento ambiental de petróleo e gás offshore, tendo como foco de sua atuação a avaliação, a compensação e a mitigação dos impactos da produção de petróleo e gás sobre comunidades em situação de vulnerabilidade, principalmente, comunidades de pesca artesanal.

Email: patriciarodin@gmail.com

ORCID: 0000-0003-4044-8144

Submissão: 23 de dezembro de 2020.

Aprovação: 2 de agosto de 2021.

Como citar: RODIN, P. Interseccionalidade em uma zona de sacrifício do capital: a experiência de mulheres negras, quilombolas e marisqueiras de Ilha de Maré, baía de Todos os Santos (Bahia, Brasil). Revista brasileira de estudos urbanos e regionais. v. 23, E202133pt, 2021. DOI 10.22296/2317-1529.rbeur.202133pt

Artigo licenciado sob Licença Creative Commons CC BY 4.0.

https://creativecommons.org/licenses/by/4.o/deed.pt_BR 